\title{
A multi-needle-assisted transformation of soybean cotyledonary node cells
}

\author{
Ren-Gao Xue $\cdot$ Hong-Feng Xie $\cdot$ Biao Zhang \\ Jong-Joo Cheong · Yang Do Choi
}

Published online: 7 November 2006

(C) Springer Science+Business Media B.V. 2006

\section{Erratum to: Biotechnol Lett (2006) 28: 1551-1557 DOI 10.1007/s10529-006-9123-6}

The paper published in Biotechnology Letters (2006, 28:1551-1557) regretfully appeared with an incorrect listing of authors and an incomplete Acknowledgements section. The correct list of authors and the complete Acknowledgements section are shown below.

Acknowledgements This work was supported by a grant from the Crop Functional Genomics Center, Korea (to Cheong) and in part by a grant from the Scigen Harvest Co., Korea (to Choi). It was also supported by grants from Shandong Provincial Education Department and from Laiyang Agricultural College, China.

The online version of the original article can be found at http://dx.doi.org/10.1007/s10529-006-9123-6.

R.-G. Xue · H.-F. Xie - B. Zhang

Department of Life \& Science, Laiyang Agricultural College, Qingdao 266109, China

J.-J. Cheong · Y. D. Choi ( $₫)$

School of Agricultural Biotechnology, Seoul National

University, Seoul 151-921, Korea

e-mail: choiyngd@snu.ac.kr

R.-G. Xue

e-mail: xuerengao@163.com 